\title{
KEMENANGAN DONALD TRUMP SEBAGAI PRESIDEN AMERIKA SERIKAT KE-45 MELALUI ANALISIS KONSTRUKSI KLAUSA RELATIF BAHASA INGGRIS DAN BAHASA INDONESIA SECARA SEMANTIS
}

\author{
Aldila Arin Aini' ${ }^{1}$, Islamiah Bastiar' ${ }^{2}$, Sumarlam ${ }^{3}$ \\ ${ }^{1,2}$ Mahasiswa Program Studi S2 Linguistik, Pascasarjana Universitas Sebelas Maret \\ ${ }^{3}$ Guru Besar Linguistik Universitas Sebelas Maret, Surakarta, Indonesia \\ 1arinaini92@gmail.com; ${ }^{2}$ miabastiar@ rocketmail.com; ${ }^{3}$ sumarlam@staff.uns.ac.id
}

\begin{abstract}
This research aims (1) to comprehend the relative construction of English and Indonesia language on some texts relating to Donald Trump is elected as the $45^{\text {th }}$ President of USA in 2016 semantically, and (2) to describe the analysis of relative constructive clauses between English and Indonesia language semantically. The research method is descriptive qualitative. Meanwhile, method of collecting data is agih method and the techniques are substitution, expand, interuption, and mutation. Based on the texts relating to Donald Trump is elected as the President of USA in 2016, it is found that the analysis of relative constructive clause of English and Indonesia language is based on the use of conjunction. In Indonesia language texts, there is one conjuction, namely: "yang", meanwhile in English language texts, there are five conjuctions, namely: "who, whom, which, whose, and that". If it is viewed from its semantics adjacent, relative clause can be divided into two sections based on its orthographics, namely: (1) restrictive relative clause which refers to the explained antecedent or as the integral unity from antecedent and unmarked by comma, and (2) non-restrictive relative clause as the additional information from antecedent explained and marked by comma.
\end{abstract}

Keywords: relative clause of English, relative clause of Indonesia language, restrictive relative clause, and non-restrictive relative clause.

\begin{abstract}
ABSTRAK
Penelitian ini bertujuan (1) untuk memahami konstruksi klausa relatif bahasa Inggris dan bahasa Indonesia pada beberapa teks yang berhubungan dengan terpilihnya Donald Trump sebagai Presiden Amerika Serikat yang ke-45 di tahun 2016 secara semantis, dan (2) untuk mendeskripsikan analisis kontruksi klausa relatif antara bahasa Inggris dan bahasa Indonesia secara semantis. Metode penelitian yang digunakan pada penelitian ini adalah metode deskriptif kualitatif. Adapun metode yang digunakan adalah metode agih dan teknik dalam pengumpulan data pada penelitian ini adalah teknik lanjutan dalam metode agih, diantaranya teknik ganti, teknik perluas, teknik sisip dan teknik balik. Berdasarkan hasil penelitian yang ditemukan pada beberapa wacana berbahasa Inggris dan Indonesia yang berhubungan dengan terpilihnya Donald Trump sebagai Presiden Amerika Serikat di tahun 2016, ditemukan bahwa analisis konstruktif klausa relatif antara bahasa Inggris dan bahasa Indonesia berdasarkan pada penggunaan konjungsi. Hal tersebut ditemukan dalam teks berbahasa Indonesia yang hanya ditemukan satu kata, yaitu "yang", sedangkan dalam teks berbahasa Inggris ditemukan lima kata, yaitu "who, whom, which, whose, dan that". Jika dilihat dari
\end{abstract}


sisi semantis teks tersebut, klausa relatif bisa dibedakan menjadi dua berdasarkan ortografisnya, yaitu (1) klausa relatif restriktif yang mewatasi makna anteseden yang diterangkan atau sebagai kesatuan integral dari anteseden dan tidak ditandai dengan adanya tanda koma, dan (2) klausa relatif non-restriktif sebagai informasi tambahan dari anteseden yang diterangkan dan ditandai oleh tanda koma.

Kata kunci: klausa relatif bahasa Inggris, klausa relatif bahasa Indonesia, klausa relatif restriktif, klausa relatif non-restriktif.

\section{PENDAHULUAN}

Terpilihnya Donald Trump sebagai Presiden Amerika Serikat ke-45 mengejutkan dunia khususnya warga Amerika Serikat. Trump berhasil menaklukan pesaingnya dari partai demokrat, Hillary Clinton, dengan masing-masing perolehan suara 279-228 melalui electoral vote pada tanggal 8 November 2016. Akan tetapi, setelah beberapa hari kemudian terjadi aksi protes atas kemenangan Trump dikarenakan pernyataanpernyataan dari Trump yang sangat kontroversial seperti dalam pidato Trump yang menyebut warga Meksiko sebagai penjahat atau pemerkosa dan berjanji akan membangun tembok di wilayah perbatasan kedua negara tersebut, meremehkan keluarga dari mendiang seorang tentara muslim AS yang meninggal di Irak pada tahun 2004, dan bahkan melarang para imigran yang dianggap Trump legal untuk tetap tinggal di negara adidaya tersebut. Walaupun Melania Trump juga imigran dari Slovenia, hal ini tidak menyurutkan Trump untuk melarang imigran legal tinggal di negaranya. Kebijakan lainnya juga menyulitkan negara lain untuk menjalin kerjasama dengan AS karena Trump lebih fokus untuk mengelola hubungan dalam negeri daripada hubungan luar negeri. Kebijakan-kebijakan Trump yang masih sangat sulit diterima dunia khususnya warga AS sendiri, menjadi objek yang menarik bagi peneliti untuk menganalisis kemenangan Trump dalam pemilu AS 2016 melalui analisis konstruksi klausa relatif secara semantis.

Klausa merupakan satuan gramatikal yang berupa kelompok kata, yang berpotensi menjadi kalimat. Klausa adalah suatu satuan yang terdiri dari subjek dan predikat. Subjek dan predikat tersebut, dapat disertai objek, pelengkap, dan keterangan, atau dapat juga tidak disertai dengan ketiga hal tersebut. Klausa berbeda dengan kalimat, sebab Klausa tidak mengandung jeda, intonasi, tempo, dan nada, seperti dalam sebuah kalimat. Dalam klausa terdapat beberapa jenis klausa, salah satunya klausa 
relatif. Klausa relatif dibagi menjadi dua berdasarkan struktur klausa relatif dan tipetipe klausa relatif. Pada struktur klausa relatif terdapat permarkah Yang, sedangkan pada tipe-tipe klausa relatif terdapat klausa restrektif dan non-restriktif.

\section{TEORI DAN METODOLOGI}

\section{Klausa}

Chaer (2008) menyatakan klausa merupakan runtunan kata-kata berkonstruksi predikatif dan satuan sintaksisnya berada di bawah satuan kalimat dan berada di atas satuan frasa. Dalam Bahasa Indoensia, klausa dapat dibedakan berdasarkan kategori dan tipe kategori yang menjadi predikatnya, maka kita dapat menyebut adanya klausa nominal, klausa verbal, klausa ajektival, klausa preposisional dan klausa numeral. Lebih lanjut, Chaer (2009:150) menambahkan klausa adalah satuan sintaksis yang bersifat predikatif. Artinya, didalam satuan atau konstruksi itu terdapat sebuah predikat, bila dalam satuan itu tidak terdapat predikat, maka satuan itu bukan sebuah klausa.

Selain itu, Alwi (2003:39) menyatakan istilah klausa dipakai untuk merujuk pada deretan kata yang paling tidak memiliki subjek dan predikat, tetapi belum memiliki intonasi atau tanda baca tertentu. Istilah kalimat juga mengandung unsur paling tidak memiliki subjek dan predikat, tetapi sudah dibubuhi intonasi atau tanda baca tertentu. Selanjutnya, Alwi, dkk. (2003:391) menambahkan bahwa kalimat luas tidak setara dapat pula disusun dengan memperluas salah satu fungsi sintaksisnya (fungsi S, P, O, dan Ket) dengan klausa. Perluasan itu dilakukan dengan menggunakan yang. Klausa perluasan dengan yang yang disematkan dalam klausa utama disebut klausa relatif dan berfungsi sebagai keterangan bagi fungsi sintaktis tertentu.

\section{Klausa Relatif}

\subsection{Jenis Klausa Relatif}

Klausa relatif dibagi menjadi dua, yaitu klausa relatif restriktif dan non-restriktif (Alwi, at al, 2003: 12, Quirk, et.al, 2000: 1246).

\subsubsection{Klausa Relatif Restriktif}

Klausa relatif ini mewatasi makna anteseden yang diterangkan atau sebagai kesatuan atau integral dari anteseden. Klausa relatif restriktif ini tidak ditandai tanda koma. Seperti pada contoh berikut ini: 
(1) Jika pernyataan tentang kaum muslim telah dihapus dari situs resmi kampanye Trump, maka ada beberapa rencana kebijakannya yang masih tetap berada di dalam situs tersebut.

(2) Trump thanked Obama for the meeting which he said had originally been scheduled for 10 minutes and went on for 90 .

\subsubsection{Klausa Relatif Non-restriktif}

Klausa relatif ini hanya sebagai informasi tambahan dari anteseden yang diterangkan. Klausa relatif restriktif ini ditandai oleh tanda koma. Seperti pada contoh:

(3) Dalam wawancaranya dengan CNBC, bahkan Al-Waleed juga menyebut Trump juga telah menghapus komentar sinisnya kepada kaum muslim, yang pernah diunggah dalam akun twitternya.

(4) Trump, who spent years pursuing Obama over false claims he is not a natural-born American and accused him of being the founder of ISIS on the campaign trail, called Obama a "very good man" and said he would seek his counsel in future.

Pada penelitian ini penulis menggunakan beberapa teks berbahasa Inggris dan berbahasa Indonesia yang berhubungan dengan terpilihnya Donald Trump sebagai Presiden Amerika Serikat di tahun 2016 dimana teks berita berbahasa Inggris berjumlah lima dikutip dari CNN International dan teks berita berbahasa Indonesia berjumlah dua dikutip dari CNN Indonesia yang masing-masing diterbitkan dalam waktu yang berbeda.

Model penelitian ini adalah model atau jenis penelitian deskriptif kualitatif. Jenis penelitian ini menekankan pada proses analisis secara induktif. Disebut induktif karena penelitian kualitatif ini tidak menganalisis data setelah beberapa waktu pengumpulan data. Sebaliknya, analisis penelitian kualitatif dilakukan setelah menumakan data (Lincoln \& Guba dalam Santosa 2014).

Pengumpulan data diperoleh dengan metode agih. Metode agih menggunakan alat penentu dasar bahasa yang diteliti. Dasar penentu di dalam kerja metode agih adalah teknik pemilihan data berdasarkan kategori tertentu dari segi kegramatikalan sesuai dengan ciri-ciri yang dimiliki oleh data penelitian (Sudaryanto, 2015: 38).

Teknik lanjutan yang digunakan dalam metode agih, diantaranya teknik ganti yang berupa penggantian unsur satuan lingual data, teknik perluas yang berupa perluasan unsur satuan lingual data, teknik sisip yang berupa penyisipan unsur satuan 
lingual data diantara unsur-unsur lingual yang ada dan teknik balik yang berupa pembalikan unsur satuan lingual data.

\section{TEMUAN DAN PEMBAHASAN}

Analisis konstruksi klausa relatif bahasa Inggris dan bahasa Indonesia secara ortografis dibagi menjadi dua yaitu klausa relatif restriktif yang tidak ditandai oleh tanda koma dan klausa relatif nonrestriktif yang ditandai oleh tanda koma. Perbandingan antara kedua jenis klausa relatif tersebut dapat dilihat pada analisis berikut ini:

(5a) A Russian official told CNN Thursday that the Russian Foreign Ministry had offered to establish contact with both the Clinton and Trump teams in the run up to the US election. It's a move which the Ministry says is normal diplomatic practice "to maintain relations with the two obvious candidates."

Klausa relatif restriktif bahasa Inggris yang terdapat dalam kalimat (5a) adalah which the Ministry says is normal diplomatic practice "to maintain relations with the two obvious candidates". Klausa relatif ini mewatasi makna makna anteseden yang diterangkan yaitu Departemen Luar Negeri Rusia. Secara semantis, akan berbeda halnya apabila klausa relatif restriktif dalam kalimat tersebut diubah menjadi klausa relatif non-restriktif sehingga menjadi:

(5b) A Russian official told CNN Thursday that the Russian Foreign Ministry had offered to establish contact with both the Clinton and Trump teams in the run up to the US election. It's a move, which the Ministry says is normal diplomatic practice "to maintain relations with the two obvious candidates."

Klausa relatif non-restriktif bahasa Inggris yang terdapat dalam kalimat (5b) adalah, which the Ministry says is normal diplomatic practice "to maintain relations with the two obvious candidates. Klausa relatif ini mewatasi makna anteseden yang diterangkan yaitu Departemen Luar Negeri Rusia. Kesatuan atau integral dari anteseden tersebut menjelaskan Departemen Luar Negeri Rusia yang menawarkan diri untuk bekerjasama dengan Clinton dan Trump pada pertemuan pilpres AS yaitu, Departemen Luar Negeri Rusia yang diketuai oleh Vladimir Putin. Pada kalimat (5a) dan (5b) menggunakan konjungsi which karena pada kedua kalimat tersebut pewatasan maknanya berupa kata benda. 
(6a) The military leadership of our country feels good about it and all of those people have skills and expertise that our military needs.

Klausa relatif restriktif bahasa Inggris yang terdapat dalam kalimat (6a) adalah that our military needs. Klausa relatif ini mewatasi makna anteseden yang diterangkan yaitu masyarakat Amerika yang mempunyai kemampuan dan keahlian. Secara semantis, akan berbeda halnya apabila klausa relatif restriktif dalam kalimat tersebut diubah menjadi klausa relatif non-restriktif sehingga menjadi;

(6b) The military leadership of our country feels good about it and all of those people have skills and expertise, that our military needs.

Klausa relatif non-restriktif bahasa Inggris yang terdapat dalam kalimat (6b) adalah, that our military needs. Klausa relatif ini mewatasi makna anteseden yang diterangkan yaitu masyarakat Amerika yang mempunyai kemampuan dan keahlian. Kesatuan atau integral dari anteseden tersebut menjelaskan semua masyarakat Amerika yang mempunyai kemampuan dan keahlian yang dibutuhkan oleh tentara AS. Pada kalimat (6a) dan (6b) menggunakan konjungsi that karena pada kedua kalimat tersebut pewatasan maknanya merupakan subjek dalam kalimat majemuk setara. Di sisi lain, penggunaan konjungsi who, whom, which dan whose juga dapat digantikan dengan that.

(7a) Here are stories from some imagination who fear what a Trump presidency could bring.

Klausa relatif restriktif bahasa Inggris yang terdapat dalam kalimat (7a) adalah who fear what a Trump presidency could bring. Klausa relatif ini mewatasi makna anteseden yang diterangkan yaitu pernyataan dari para imigran AS yang takut apabila Trump menjadi Presiden AS. Secara semantis, akan berbeda halnya apabila klausa relatif restriktif dalam kalimat tersebut diubah menjadi klausa relatif non-restriktif sehingga menjadi;

(7b) Here are stories from some immigrants, who fear what a Trump presidency could bring.

Klausa relatif non-restriktif bahasa Inggris yang terdapat dalam kalimat (7b) adalah, who fear what a Trump presidency could bring. Klausa relatif ini mewatasi makna 
anteseden yang diterangkan yaitu pernyataan dari para imigran AS yang takut apabila Trump menjadi Presiden AS. Kesatuan atau integral dari anteseden tersebut menyebutkan identitas para imigran diantaranya Karina Ruiz (23), Matt Lee (25), Dora Rodriguez (27), Alicia Ramirez dan Michael Nazario (27) yang masing-masing mengungkapkan ketakutan dan kecemasan mereka akan kebijakan Trump tentang deportasi. Pada kalimat (7a) dan (7b) menggunakan konjungsi who karena pada kedua kalimat tersebut pewatasan maknanya berupa pelaku dan nama orang yang berkedudukan sebagai subjek dalam kalimat majemuk bertingkat.

(8a) Jeff Sessions of Alabama, retired Army Lt. Gen, Mike Flynn, former New York City Mayor Rudy Giuliani, Dr. Ben Carson and former House Speaker Newt Gingrich all of whom have been close confidantes of the billionaire during his presidential campaign.

Klausa relatif restriktif bahasa Inggris yang terdapat dalam kalimat (8a) adalah all of whom have been close confidantes of the billionaire during his presidential campaign Klausa relatif ini mewatasi makna anteseden yang diterangkan yaitu sidang Jeff dari Alabama, memecat Army Lt. Gen, Mike Flynn, mantan walikota New York City Rudy Giuliani, Dr. Ben Carson dan mantan pembawa berita Newt Gingrich. Secara semantis, akan berbeda halnya apabila klausa relatif restriktif dalam kalimat tersebut diubah menjadi klausa relatif non-restriktif sehingga menjadi;

(8b) Jeff Sessions of Alabama, retired Army Lt. Gen, Mike Flynn, former New York City Mayor Rudy Giuliani, Dr. Ben Carson and former House Speaker Newt Gingrich, all of whom have been close confidantes of the billionaire during his presidential campaign.

Klausa relatif non-restriktif bahasa Inggris yang terdapat dalam kalimat (8b) adalah, all of whom have been close confidantes of the billionaire during his presidential campaign. Klausa relatif ini mewatasi makna anteseden yang diterangkan yaitu sidang Jeff dari Alabama, memecat Army Lt. Gen, Mike Flynn, mantan walikota New York City Rudy Giuliani, Dr. Ben Carson dan mantan pembawa berita Newt Gingrich adalah para bilionare pendukung kampanye Trump tahun 2016. Pada kalimat (8a) dan (8b) menggunakan konjungsi whom karena pada kedua kalimat tersebut pewatasan maknanya berupa pelaku dan nama orang yang berkedudukan sebagai objek dalam kalimat majemuk bertingkat. 
(9a) A third board members is Joseph Cinque, also known as "Joey No Socks," a convicted felon whose American Academy of Hospitality Sciences has awarded more than a dozen Trump businesses with shiny plaques called "Star Diamond" award.

Klausa relatif restriktif bahasa Inggris yang terdapat dalam kalimat (9a) adalah whose American Academy of Hospitality Sciences has awarded more than a dozen Trump businesses with shiny plaques called "Star Diamond" award. Klausa relatif ini mewatasi makna anteseden yang diterangkan yaitu Joseph Cinque yang juga dikenal sebagai Joey No Socks sebagai mantan narapidana dan merupakan anggota dewan pengurus ketiga. Secara semantis, akan berbeda halnya apabila klausa relatif restriktif dalam kalimat tersebut diubah menjadi klausa relatif non-restriktif sehingga menjadi;

(9b) A third board members is Joseph Cinque, also known as "Joey No Socks," a convicted felon, whose American Academy of Hospitality Sciences has awarded more than a dozen Trump businesses with shiny plaques called "Star Diamond" award.

Klausa relatif non-restriktif bahasa Inggris yang terdapat dalam kalimat (9b) adalah, whose American Academy of Hospitality Sciences has awarded more than a dozen Trump businesses with shiny plaques called "Star Diamond" award. Klausa relatif ini mewatasi makna anteseden yang diterangkan yaitu Joseph Cinque yang juga dikenal sebagai Joey No Socks sebagai mantan narapidana dan merupakan anggota dewan pengurus ketiga ini menerima penghargaan "Star Diamond" dengan menerima selusin lebih bisnis milik Trump pada tahun 2016. Pada kalimat (9a) dan (9b) menggunakan konjungsi whom karena pada kedua kalimat tersebut pewatasan maknanya berupa kata ganti kepemilikan dalam kalimat majemuk bertingkat.

(10a)Dalam pernyataan resminya, Meredith mengaku bersalah karena tidak pernah mengecek apakah kalimat yang ditulisnya sama dengan pidato Michelle Obama.

Klausa relatif restriktif bahasa Indonesia yang terdapat dalam kalimat (10a) adalah yang ditulisnya sama dengan pidato Michelle Obama. Klausa relatif ini mewatasi makna anteseden yang diterangkan yaitu kalimat yang ditulis Meredith sama dengan pidato Michelle Obama. Secara semantis, akan berbeda halnya apabila klausa relatif restriktif dalam kalimat tersebut diubah menjadi klausa relatif non-restriktif sehingga menjadi; 
(10b) Dalam pernyataan resminya, Meredith mengaku bersalah karena tidak pernah mengecek apakah kalimat, yang ditulisnya sama dengan pidato Michelle Obama.

Klausa relatif non-restriktif bahasa Inggris yang terdapat dalam kalimat (10b) adalah, yang ditulisnya sama dengan pidato Michelle Obama. Klausa relatif ini mewatasi makna anteseden yang diterangkan yaitu bagian kalimat yang ditulis oleh Meredith yang terbukti mengutip kalimat pidato dari Michelle Obama tahun 2008 silam.

Berikut adalah penggalan kalimat pidato yang ditulis oleh Meredith; "Orangtua saya menekankan nilai-nilai, bahwa saya harus bekerja keras untuk mendapatkan apa yang saya inginkan dalam kehidupan. Kata-katamu adalah ikatan dan kamu harus lakukan apa yang kamu katakan dan tepati janji," ujar Melania.

Pengutipan kalimat pidato yang ditulis oleh Meredith tersebut terbukti sama dengan kalimat pidato Michelle Obama tahun 2008 silam, sebagaimana yang tertera pada kalimat berikut ini;

"Barack dan saya dibesarkan dalam nilai-nilai yang sama yaitu bekerja keras untuk mendapatkan apa yang kami inginkan dalam kehidupan, katakata kami adalah ikatan dan kami harus melakukan apa yang kami katakan," kata Michelle kala itu.

Kalimat lain juga membuktikan bahwa Meredith mengutip kalimat pidato Michelle Obama tahun 2008 silam seperti yang ada pada kalimat berikut ini;

"Saya harus memperlakukan orang lain dengan penuh hormat. Mereka juga mengajarkan untuk menunjukkan nilai-nilai dan moral dalam kehidupan sehari-hari. Itulah pelajaran yang saya juga berikan kepada putra saya," tambah Melania.

Walaupun tidak sepenuhnya sama, Meredith telah terbukti mengutip klausa pertama pada kalimat pidato Michelle Obama tahun 2008 silam seperti yang tertera pada kalimat berikut ini;

"Kami harus memperlakukan orang lain dengan penuh hormat dan harga diri, bahkan terhadap orang yang tak kami kenal dan bahkan di saat kami tak sependapat dengan orang itu," tambah Michelle.

\footnotetext{
Kalimat lain dari Meredith yang terbukti mengutip kalimat pidato Michelle Obama yaitu;

"Sebab, kami menginginkan anak-anak kami di negeri ini memahami bahwa satu-satunya yang membatasi raihanmu adalah kekuatan mimpi dan keinginanmu mewujudkan mimpi itu," kata perempuan kelahiran Slovenia itu
} 
Pada kalimat (10a) dan (10b) menggunakan konjungsi yang dan pada kedua kalimat tersebut pewatasan maknanya berupa klausa nomina.

(11a) Seorang staf penulis Organisasi Trump yang dimiliki oleh Donald Trump telah mengaku bertanggungjawab karena sudah menyisipkan penggalan kalimat yang merupakan bagian dari pidato Michelle Obama pada 2008 silam, dalam naskah sambutan Melania Trump saat pembukaan Konvensi Nasional Partai Republik.

Klausa relatif restriktif bahasa Indonesia yang terdapat dalam kalimat (11a) adalah yang dimiliki oleh Donald Trump telah mengaku bertanggungjawab karena sudah menyisipkan penggalan kalimat yang merupakan bagian dari pidato Michelle Obama pada 2008 silam, dalam naskah sambutan Melania Trump saat pembukaan Konvensi Nasional Partai Republik. Klausa relatif ini mewatasi makna anteseden yang diterangkan yaitu seorang staf penulis Organisasi Trump yang mengaku bertanggungjawab karena sudah menyisipkan penggalan kalimat yang merupakan bagian dari pidato Michelle Obama pada 2008.

(11b)Seorang staf penulis Organisasi Trump, yang dimiliki oleh Donald Trump, telah mengaku bertanggungjawab karena sudah menyisipkan penggalan kalimat yang merupakan bagian dari pidato Michelle Obama pada 2008 silam, dalam naskah sambutan Melania Trump saat pembukaan Konvensi Nasional Partai Republik.

Klausa relatif non-restriktif bahasa Inggris yang terdapat dalam kalimat (11b) adalah , yang dimiliki oleh Donald Trump,. Klausa relatif ini mewatasi makna anteseden yang diterangkan yaitu staf penulis Organisasi Trump yang bernama Meredith. Pada kalimat (11a) dan (11b) menggunakan konjungsi yang dan pada kedua kalimat tersebut pewatasan maknanya berupa klausa verbal. 


\section{SIMPULAN}

Dari penjelasan sebelumnya dapat disimpulkan bahwa analisis konstruksi Bahasa Inggris dan Bahasa Indonesia dapat dibedakan dari penggunaan konjungsi dimana dalam bahasa Indonesia hanya ditemukan yang, sementara dalam bahasa Inggris beberapa seperti who, whom, which, whose, dan that seperti yang ditemukan dalam wacana kemenangan Donald Trump sebagai presiden Amerika Serikat ke-45. Di dalam analisis ini, ditemukan dua klausa realtif Bahasa Indonesia dan lima klausa relatif bahasa Inggris dimana masing-masing mempunyai perbedaan makna yang ditandai ada atau tidaknya tanda koma.

\section{DAFTAR PUSTAKA}

Alwi, H et al. (1998). Tata bahasa baku Bahasa Indonesia. Jakarta: Balai Pustaka.

Alwi, H., et al. (2003). Tata bahasa baku Bahasa Indonesia: Edisi Ketiga. Jakarta: Balai Pustaka.

Chaer, A. (2008). Morfologi bahasa Indonesia (pendekatan proses). Jakarta: Rineka Karya.

Chaer, A. (2009). Sintaksis bahasa Indonesia (pendekatan proses). Jakarta: Rineka Cipta.

Comrie, B. (1981). Language universals and linguistics tipology: syntax and morpology. Oxford: Basil Blackwell.

Quirk, R., \& Greenbauuwn, S. (1976). Comprehension grammar of the English language. New York: Longman.

Santosa, R. (2014). Metode penelitian kualitatif kebahasaan. Surakarta: Universitas Sebelas Maret.

Sudaryanto. (2015). Metode dan aneka teknik analisa bahasa. Yogyakarta: Sanata Dharma University Press.

CNN. (2016, November).Trump. http://edition.cnn.com/2016/11/10/us/mlk-crypttrump-reaction diakses pada tanggal 11 November 2016 Pukul 19.07 WIB.

CNN. (2016, November). Trump transition.

http://edition.cnn.com/2016/11/11/politics/pence-will-lead-trump-transition diakses pada tanggal 10 November 2016 Pukul 20.23 WIB. 
CNN. (2016, November). Lgbt. http://edition.cnn.com/2016/11/11/politics/trumpvictory-lgbt-concerns diakses pada tanggal 11 November Pukul 20.58 WIB.

CNN. (2016, November). Immigrants deportatio.

http://edition.cnn.com/news/2016/11/11/immigrants-gripped-by-deportationfears-with-trump-election diakses pada tanggal 11 November 2016 Pukul 21.09 WIB. 